\title{
O DIÁLOGO ENTRE A JURISPRUDÊNCIA INTERAMERICANA DE DIREITOS HUMANOS E O DIREITO BRASILEIRO: UMA ANÁLISE A PARTIR DA APLICAÇÃO DO CONCEITO DE "DANO AO PROJETO DE VIDA"
}

\author{
Ana Paula Matos de Queiroz ${ }^{147}$ \\ Yara Maria Pereira Gurgel ${ }^{148}$
}

Recebido em: 30/11/2016

Aprovado em: 17/10/2017

\begin{abstract}
RESUMO
o presente trabalho se destina a analisar o diálogo entre a jurisprudência americana em matéria de direitos humanos, especialmente os acórdãos da Corte Interamericana de Direitos Humanos, e o direito doméstico, através de pesquisa bibliográfica baseada em doutrina, jurisprudência nacional e internacional e, ainda, nas legislações brasileira e interamericana. Para tanto, será utilizado o exemplo do conceito de dano ao projeto de vida, aplicado pela Corte Interamericana, e o seu paralelo no direito brasileiro, o dano existencial. Dessa forma, primeiramente, se conceituará o dano ao projeto de vida, demonstrando o tratamento dado ao instituto pela Corte Interamericana, defende-se, em seguida, a utilização da jurisprudência interamericana enquanto fonte do direito estatal. Em seguida, se tratará do instituto do dano existencial, abordando, especialmente, a sua aplicação pelo direito de trabalho, no sentido de verificar se os tribunais trabalhistas pátrios estão fazendo a devida observância da jurisprudência interamericana.
\end{abstract}

Palavras-chaves: Corte Interamericana. Jurisprudência. Dano ao projeto de vida. Dano existencial.

\section{INTRODUÇÃO}

Estudar Direito Internacional, no Brasil, é um desafio. Assim o é, pois, ainda subsistem a cultura acadêmica e, sobretudo, a tradição jurídica que relegam à disciplina o

\footnotetext{
${ }^{147}$ Mestranda em Direito Constitucional pela Universidade Federal do Rio Grande do Norte. Advogada. 148 Doutora em Direito, subárea Direito do Trabalho, pela Pontifícia Universidade Católica de São Paulo PUC/SP. Mestre em Direito das Relações Sociais, subárea Direito do Trabalho, pela Pontifícia Universidade Católica de São Paulo - PUC/SP. Advogada.
} 
papel de matéria alheia à vida do homem médio, sem aplicabilidade imediata e sem a capacidade de se imiscuir no cotidiano do cidadão comum.

Além disso, estudar o Direito Internacional a partir do ponto de vista do reconhecimento de uma jurisdição internacional se revela enquanto uma tarefa ainda mais permeada por obstáculos. Isso porque os agentes do direito interno tendem a atribuir às decisões advindas da esfera internacional caráter de mera recomendação - um raciocínio que, quando aplicado às sentenças internacionais, se mostra de todo inadequado.

As decisões oriundas dos tribunais internacionais são o fruto primário da tutela jurisdicional destinada ao controle das obrigações que surgem a partir das normas internacionais que emergem a partir dos tratados.

Especificamente, no caso dos países ratificadores da Convenção Americana sobre Direitos Humanos (CADH) e que aceitaram se submeter à jurisdição da Corte Interamericana de Direitos Humanos (Corte IDH), as sentenças internacionais são o fruto da tutela jurisdicional interamericana de direitos humanos.

Em uma conceituação simples de direito interno, é possível descrever a tutela jurisdicional como a função do Estado - sendo privativa deste - que se destina a resolver os conflitos existente no seu âmbito de atuação jurídica, desde que esses estejam abarcados pela zona de regulação das normas estatais e estejam dentro da esfera de interesse do Estado.

Neste sentido, como é possível afirmar que há uma jurisdição internacional quando não existe um "Super Estado", ao qual se submetem todos os demais? A jurisdição internacional é o produto da submissão voluntária dos próprios Estados que, coletivamente, decidiram pela necessidade da existência de órgãos judicantes supranacionais e imparciais, destinados à aplicar as leis internacionais a um caso concreto, resolvendo conflitos entre: pessoas e Estados, como é o caso dos tribunais internacionais de direitos humanos; Estados e Estados, função atribuída à Corte Internacional de Justiça; ou entre pessoas e a sociedade internacional, situação que se observa no Tribunal Penal Internacional.

Aplicando essa lógica a tutela internacional dos Direitos Humanos no continente americano, se percebe que tutela jurisdicional interamericana dos Direitos Humanos é fruto da vontade coletiva dos Estados-membros da Organização dos Estados Americanos, ratificadores da Convenção Americana sobre Direitos Humanos e que aceitaram a jurisdição contenciosa da Corte Interamericana de Direitos Humanos, órgão judicante supranacional e imparcial da América destinado a resolver os conflitos entre Estados e pessoas, relativos aos direitos e garantias protegidos pelas normas do Sistema Interamericano de Proteção dos Direitos Humanos. 
O Brasil ratificou a Convenção Americana sobre Direitos Humanos em 1992 e aceitou se submeter à competência da Corte Interamericana de Direitos Humanos em 1998. Logo, o Brasil se obriga a respeitar todas as normas contidas na CADH e a cumprir todas as sentenças da Corte IDH que lhe atribuam alguma obrigação.

A Corte IDH, como qualquer outro tribunal, possui a sua jurisprudência. Sendo assim, surge a seguinte questão: os juízes e tribunais brasileiros devem necessariamente levar em conta a jurisprudência da Corte Interamericana de Direitos Humanos enquanto parâmetro para interpretação e aplicação em matéria de direitos humanos? Se sim, é possível afirmar que esse dever de observância é respeitado no Brasil?

$\mathrm{Na}$ tentativa de responder essa pergunta, o presente trabalho analisará a questão a partir do prisma da aplicação do conceito de "dano ao projeto de vida" no direito interno, que se dá através da figura do dano existencial, através de pesquisa bibliográfica baseada em doutrina, jurisprudência nacional e internacional e, ainda, nas legislações brasileira e interamericana. Para tanto, serão apresentados os conceitos de ambos os institutos jurídicos; se analisará a possibilidade de entender a jurisprudência da Corte Interamericana enquanto fonte do direito estatal; e, ainda, observar-se-á a forma de aplicação do dano existencial no direito pátrio, analisando-se, por fim, se os juízes e tribunais nacionais estão tratando o dano existencial tal qual a Corte Interamericana trata o dano ao projeto de vida.

\section{O "DANO AO PROJETO DE VIDA"}

De pronto, se mostra importante analisar o conceito de dano ao projeto de vida, sobretudo a maneira como este é interpretado pela jurisprudência interamericana.

Segundo Sergio García Ramírez, a noção de dano ao projeto de vida orbita em torno da ideia de realização pessoal e desenvolvimento individual (RAMIREZ, 2006, 218). Sendo assim, sofre dano ao projeto de vida toda aquela pessoa que viu o resultado provável de sua vida ser negativamente alterado por ação ou omissão estatal.

2.1 O reconhecimento do "dano ao projeto de vida" na jurisprudência da Corte Interamericana de Direitos Humanos

Conforme nos ensina André de Carvalho Ramos (RAMOS, 2005, p.58), o dano ao projeto de vida se distingue do dano emergente e do lucro cessante, uma vez que não se trata 
de lesão patrimonial diretamente derivada do ato violador e nem tampouco de perda de ingressos econômicos futuros, o que é possível de ser quantificado através de determinados indicadores objetivos. O projeto de vida diz respeito a toda realização de um ser humano, levando em conta possíveis ganhos econômicos futuros e outras variantes subjetivas, como o potencial individual, a aptidão, a vocação e os anseios diversos de cada pessoa.

Logo, está o conceito de dano ao projeto de vida diretamente ligado a idéia de prejuízo à expectativa de desenvolvimento pessoal.

A Corte Interamericana se pronunciou pela primeira vez à respeito do tema no caso “Loayza Tamayo Vs. Peru”, concluindo que as circunstâncias da detenção da vítima tenham causado dano a sua perspectiva de auto-realização plena, não estando uma reclamação de dano ao projeto de vida ligada à relação da pessoa com seu patrimônio. Ainda, acrescentaram os juízes que "um indivíduo não é verdadeiramente livre se não tiver opções para a sua vida, as quais se revestem de 'um importante valor existencial', cuja perda a Corte 'não pode ignorar"”' (TRINDADE, 2003, p. 76).

Outros diversos casos da Corte Interamericana reconheceram o dever de indenizar o dano ao projeto de vida. Entres estes, chamam atenção "Cantoral Benavides vs. Peru” e “Gelman vs. Uruguai” (Schäfer e Machado, 2013, p. 190). No primeiro caso mencionado, o Peru foi condenado em razão da prisão provisória ilegal de Luis Alberto Cantoral Benavides, que passou quatro anos detido, sofrendo abusos físicos e psicológicos, tendo visto a sua vida como estudante de graduação em biologia subitamente interrompida pela ação do Estado. Por entender que foram violados diversos dispositivos da $\mathrm{CADH}$, a Corte determinou ao Peru o custeio de um bolsa de estudos, além de todos os gastos necessários para a subsistência da vítima nesse período, como maneira de reparação à interrupção que o curso natural de sua vida sofreu por ocasião da prisão arbitrária (Schäfer e Machado, 2013, p. 190).

Ainda, no caso "Gelman vs. Uruguai", a Corte Interamericana condenou o Estado a indenizar a Sra. María Macarena Gelman pelos incontáveis danos sofridos quando ela, aos 24 anos, descobriu que tinha sido subtraída de sua família quando ainda estava recém nascida, sendo filha de um casal que foi clandestinamente detido, torturado e morto durante o regime autoritário que perdurou no Uruguai de 1973 a 1985 (Schäfer e Machado, 2013, p. 190).

Percebe-se que, nos dois casos, persiste o fator comum do dano em razão de alteração brusca sofrida no plano de vida. No caso peruano, a vítima viu a sua expectativa de futuro e o desenvolvimento de seu potencial pessoal frustrados pela ação do Estado. No caso uruguaio, por sua vez, a vítima foi privada de seu direito à identidade, desconhecendo às suas origens e tendo sofrido forte abalo quando finalmente passou a saber a verdadeira história de sua vida. 
O dano ao projeto de vida resulta da diferença entre o que foi e o que poderia ter sido. A intenção da reparação, neste sentido, é tentar diminuir o abismo entre a vida provável que as vítimas poderiam ter tido e a vida que estas, de fato, tiveram, em razão da violência estatal.

\subsection{O reconhecimento da jurisprudência interamericana como fonte do direito estatal}

Sendo o objetivo do presente trabalho analisar a incidência da jurisprudência interamericana no direito interno, através do conceito do dano ao projeto de vida, se mostra necessário estabelecer se a jurisprudência interamericana em matéria de humanos deve ser entendida, pelos juízes pátrios, enquanto fonte do direito estatal.

A partir dos anos finais da década de 1980 - período marcado pelo processo de redemocratização do Brasil após mais de 20 anos de um regime autoritário marcado pelo desrespeito à dignidade e seus desdobramentos - o Estado Brasileiro adotou uma nova postura no que diz respeito à proteção e promoção dos Direitos Humanos.

Com o advento do período inaugurado em 1985, em particular com a promulgação da atual Constituição da República Federativa do Brasil (CRFB/88) em 1988, o Brasil passou por mudanças que não significaram apenas modificações no plano interno, mas, também, uma guinada na agenda internacional em direção a uma postura comprometida com a inserção definitiva do país com a agenda do Direito Internacional dos Direitos Humanos (PIOVESAN, 2012, p. 361).

Uma das principais medidas oriundas desta nova atitude do Estado brasileiro para com o Direito Internacional foi a massiva incorporação de instrumentos internacionais destinados à proteção dos direitos humanos. Desde 1988, em esforço notável, o Brasil ratificou dezenas de tratados internacionais de direitos humanos, entre eles, a Convenção Americana sobre Direitos Humanos, norma base do Sistema Interamericano de Proteção dos Direitos Humanos.

Sobre o fenômeno apontado, a professora Flavia Piovesan tece a seguinte observação:

(...) Esse esforço se conjuga com o objetivo de compor uma imagem mais positiva do Estado brasileiro no contexto internacional, como país respeitador e garantidor dos direitos humanos. Adicione-se que a adesão do Brasil aos tratados internacionais de direitos humanos simboliza ainda o seu aceite para com a ideia contemporânea de globalização dos direitos humanos, bem como para com a ideia da legitimidade das preocupações da comunidade internacional no tocante à matéria. (PIOVESAN, 2012, p. 369).

Neste sentido, é possível concluir que para além de uma necessidade de compatibilização da postura do Brasil com o novo regime político interno, democrático e 
garantidor de direitos, a nova atitude brasileira foi fruto de uma necessidade de afastar do país a imagem construída nas últimas duas décadas: de um Estado latinoamericano regido por um regime antidemocrático, ofensor de direitos e, ainda, despreocupado com os anseios da comunidade internacional.

Todavia, a ratificação dos tratados internacionais de direitos humanos não foi a medida mais radical adotada pelo país com o intuito de se adequar aos parâmetros internacionais de integração e universalização de direitos e garantias.

Em 1998, o Brasil declarou à Corte o aceite de sua competência, nas esferas contenciosa e consultiva, depositando junto à Secretaria da Organização dos Estados Americanos o instrumento de aceite em 10 de dezembro de 1998 e tendo promulgado internamente o Decreto 4.463/02, em 8 de novembro de 2002, o qual traz em seu Artigo $1^{\circ}$ que o Brasil reconhece como obrigatória, de pleno direito e por prazo indeterminado, a competência da Corte Interamericana de Direitos Humanos em todos os casos relativos à interpretação ou aplicação da Convenção Americana sobre Direitos Humanos, de acordo com art. 62 do Pacto, sob reserva de reciprocidade e para fatos posteriores a 10 de dezembro de 1998.

Isso significa que, além de o Brasil incorporar ao seu ordenamento jurídico as normas da Convenção Americana sobre Direitos Humanos, o Estado Brasileiro, também, aceita que a observância quanto ao cumprimento dessas normas dentro de seu território seja exercida não só pelos órgãos nacionais, mas, também, por uma Corte Internacional, com competência para processar e julgar todos os países que estejam submetidos à sua jurisdição.

Assim, conforme já afirmado na Introdução do presente trabalho, a partir de 1998, o Brasil passa a integrar a jurisdição interamericana de direitos humanos, na figura de jurisdicionado, podendo ser, a qualquer momento, réu e, ainda, obrigado a adotar diversos tipos de medidas reparatórias, caso se entenda que, no caso em questão, o Brasil violou os direitos protegidos pelo Pacto de São José.

Logo, se entende que o Brasil possui inegável compromisso com as decisões tomadas pela Corte Interamericana de Direitos Humanos. Sendo assim, para a análise ora proposta, se mostra relevante trazer à lume o seguinte questionamento: até que ponto se estende o compromisso do Estado brasileiro com as sentenças fruto da atividade jurisdicional interamericana em matéria de direitos humanos?

De pronto, se faz necessário analisar os próprios termos da Convenção Americana sobre Direitos Humanos relacionados ao pleno entendimento da questão. O Artigo 2 da 
Convenção ${ }^{149}$, intitulado "Dever de adotar disposições de direito interno", afirma que caso o pleno gozo dos direitos e liberdades protegidos pelo tratado ainda não estiver assegurado por medidas legislativas ou de outra natureza, os Estados partes se comprometem a adotar, em conformidade com as normas constitucionais de cada país e com os termos da CADH, todas as medidas, de qualquer natureza, que se mostrem necessárias para a efetivação satisfatória das garantias em questão.

Em síntese, o dispositivo em comento impõe aos Estados a obrigação de adotar todas as medidas que se mostrem necessárias à proteção dos direitos assegurados pela Convenção. Logo, é possível afirmar que a inexistência de ações estatais, legislativas ou de outra natureza, no sentido de proteger tais direitos, seria uma ofensa à norma em questão, o que constituiria uma violação por omissão. Por outro lado, a existência de medida estatal que se mostre contrária aos ditames da Convenção Americana, constitui violação comissiva (MAZZUOLI e outro, 2013, p. 33).

Se faz necessário, portanto, que exista, no direito interno, a observância quanto à existência ou inexistência de medida que assegure ou ofenda os termos da Convenção Americana sobre Direitos Humanos, uma vez que, a inobservância, por si só, configuraria violação omissiva ao Pacto. Conforme as normas da CRFB/88, o dever de apreciar violações de direitos e garantias, estejam estes contidos em tratados internacionais ou em leis estatais, é uma das competências do poder judiciário, em suas mais variadas esferas ${ }^{150}$. Neste sentido, aliando as regras da Convenção Americana às determinações constitucionais do Estado brasileiro, nos parâmetros do que impõe o Artigo 2, ora em comento, o dever de interpretar e analisar se as medidas estatais estão sendo suficientes ou, ainda, se estão de acordo com o dever de proteger e garantir os direitos assegurados pelo Tratado, no Brasil, é tarefa dos juízes e tribunais nacionais.

Contudo, é importante ressaltar que a aplicação e interpretação dada pelo judiciário brasileiro às normas de direitos humanos do Sistema Interamericano não pode divergir do

\footnotetext{
149 “Artigo 2. Dever de adotar disposições de direito interno Se o exercício dos direitos e liberdades mencionados no artigo 1 ainda não estiver garantido por disposições legislativas ou de outra natureza, os Estados Partes comprometem-se a adotar, de acordo com as suas normas constitucionais e com as disposições desta Convenção, as medidas legislativas ou de outra natureza que forem necessárias para tornar efetivos tais direitos e liberdades."

${ }^{150}$ Apenas a título de exemplificação, cabe trazer o teor do Art. 109, V-A, da Constituição, o qual determina que: "Art. 109. Aos juízes federais compete processar e julgar: (...) V-A as causas relativas a direitos humanos a que se refere o $\S 5^{\circ}$ deste artigo;". O parágrafo quinto, por sua vez, estabelece o incidente de deslocamento de competência, postulando que " $5^{\circ}$ Nas hipóteses de grave violação de direitos humanos, o Procurador-Geral da República, com a finalidade de assegurar o cumprimento de obrigações decorrentes de tratados internacionais de direitos humanos dos quais o Brasil seja parte, poderá suscitar, perante o Superior Tribunal de Justiça, em qualquer fase do inquérito ou processo, incidente de deslocamento de competência para a Justiça Federal.”
} 
entendimento expressado pela jurisprudência da Corte Interamericana. Essa é uma repercussão do que chamamos de "efeito erga omnes" da coisa julgada no Sistema Interamericano. Ao decidir acerca de um caso, a Corte, pois, exprime uma sentença de caráter obrigatório, a qual, de pronto, produzirá efeitos entre as partes. Contudo, além disso, as sentenças da Corte Interamericana de Direitos Humanos também exprimem o posicionamento oficial do próprio Sistema Interamericano acerca da interpretação de suas normas, constituindo jurisprudência de caráter vinculante.

As sentenças da Corte, portanto, produzem efeitos indiretos para todos os Estados partes da Convenção Americana de Direitos Humanos, estabelecendo interpretações autênticas do Pacto de São José e de outros tratados do Sistema, as quais passam a integra a própria Convenção, uma vez que esta deve ser lida conforme o que foi estabelecido nestas decisões (CORAO, 2007, p. 134). Neste sentido, Carlos M. Ayala Corao (2007, p. 135), ensina que:

Desta forma, a coisa julgada dos julgamentos interamericanos tem um efeito geral ou erga omnes em relação a todos os Estados partes na Convenção Americana, na Comissão Interamericana e nas vítimas. Em outras palavras, a interpretação dos fatos, o valor da evidência, os artigos da Convenção aplicados e o dispositivo do julgamento, incluindo as medidas de reparação acordadas, têm o efeito de julgar a validade não só no caso específico decidido, mas contra casos futuros. Assim, por exemplo, a partir do julgamento de Velásquez Rodrigues, qualquer Estado parte que não investigue, sancione e repare uma violação dos direitos humanos reconhecidos na Convenção Americana e que seja processada perante a Corte Interamericana, será normalmente responsabilizada internacionalmente por tais fatos e, portanto, condenados a cumprir essas obrigações.

Em outras palavras, o efeito geral ou erga omnes da sentença impõe aos Estados a obrigação de aplicar a Convenção Americana e os demais tratados do Sistema no seu direito interno considerando não somente a norma em si, mas, também, os pronunciamentos da Corte Interamericana acerca da norma em questão. Sendo assim, buscando solucionar o questionamento anteriormente feito, para além do compromisso que o Estado brasileiro tem de cumprir as sentenças oriundas dos casos no qual for parte, derivado do que estabelece o Artigo 68 da Convenção Americana ${ }^{151}$, o Brasil, assim como todos os países que se submetem à jurisdição da Corte Interamericana de Direitos Humanos, deve levar em consideração a jurisprudência da Corte para decidir litígios sobre direitos e garantias protegidos pelo Pacto de

151 “Artigo 68 - 1. Os Estados-partes na Convenção comprometem-se a cumprir a decisão da Corte em todo caso em que forem partes." 
São José da Costa Rica ou, ainda, por outro instrumento normativo do Sistema Interamericano ao qual tenha aderido o Estado parte em questão.

É inconteste, dessa forma, o dever de observância que o Estado brasileiro possui para com a jurisprudência interamericana em matéria de direitos humanos, sendo equivocado afirmar que o compromisso dos países com as decisões da Corte se limita, exclusivamente, à obrigação de dar cumprimento às medidas determinadas em casos nos quais o Estado for alvo de condenação.

\section{A OBSERVÂNCIA DO CONCEITO DE "DANO AO PROJETO DE VIDA" NO DIREITO BRASILEIRO ATRAVÉS DO RECONHECIMENTO DO "DANO EXISTENCIAL"}

Conforme já apontado, o dano ao projeto de vida é entendido, pela Corte Interamericana de Direitos Humanos, enquanto um prejuízo à expectativa de desenvolvimento pessoal decorrente da ação ou omissão do Estado, ensejadora de violação de direitos humanos.

Sendo assim, para realizar a análise de compatibilidade ora pretendida, é preciso identificar, no direito pátrio, a existência do instituto jurídico em questão.

Muito embora não se perceba, no direito estatal, a existência de norma que discipline a questão da responsabilidade por dano ao projeto de vida, a jurisprudência nacional vem reconhecendo o dever de indenizar pela ocorrência de dano existencial, espécie de dano extrapatrimonial que, por sua semelhança com o conceito de dano ao projeto de vida, merece ser alvo do presente do estudo.

Sendo assim, o dano existencial pode ser entendido enquanto à violação simultânea a diversos aspectos da vida do indivíduo, implicando em uma modificação considerável na qualidade de vida do sujeito.

Explorando o conceito trazido por Flaviana Rampazzo Soares, em sua obra "Responsabilidade Civil por Dano Existencial", seria:

(...) Uma afetação negativa, total ou parcial, permanente ou temporária, seja a uma atividade, seja a um conjunto de atividades que a vítima do dano, normalmente, tinha como incorporado ao seu cotidiano e que, em razão do efeito lesivo, precisou modificar em sua forma de realização, ou mesmo suprimir de sua rotina. $\mathrm{O}$ dano existencial se consubstancia, como visto, na alteração relevante da qualidade de vida, vale dizer, em um "ter que agir de outra fora" ou em um "não poder mais fazer 
como antes, suscetível de repercutir, de maneira consistente, e, quiçá, permanente sobre a existência da pessoa. (SOARES, 2009, p. 44)

Do conceito em comento, se extrai que o dano existencial está diretamente ligado à ideia de pleno desenvolvimento pessoal. Sofre dano existencial, por exemplo, o jogador de futebol que, atropelado, precisa ter uma perna amputada ou, ainda, a criança hemofílica que se torna soropositivo em razão de transfusão sanguínea.

É possível afirmar, portanto, que o dano existencial implica em uma alteração substancial e inesperada nas diversas esferas - laboral, familiar, afetiva, social, etc. - do complexo de situações que constituem a vida humana, em razão da conduta lesiva de terceiro.

\subsection{A responsabilidade por "dano existencial"}

O dano existencial é categoria de dano extrapatrimonial - portanto, capaz de gerar responsabilidade e, por conseguinte, a obrigação de indenizar. Dessa forma, os seus fundamentos constitucionais e legais são os mesmos que autorizam a responsabilidade por dano moral ${ }^{152}$.

Sobre esse ponto, é importante ressaltar que o constituinte, quando fez uso da expressão dano moral, utilizou a terminologia enquanto sinônimo de dano extrapatrimonial (SOARES, 2009, p. 61), sendo assim, a interpretação que se dá à matéria deve ser extensiva e não restritiva, sobretudo porque, em matéria de direitos humanos, a norma sempre deve ser compreendida no sentido mais favorável à proteção da pessoa - e, nesse caso, entender que o termo dano moral foi empregado para designar exclusivamente os danos morais propriamente ditos, excluindo-se, portanto, da proteção constitucional todas as demais categorias de danos imateriais, seria, definitivamente, prejudicial à salvaguarda do ser humano.

Ainda, deve ser observado o que dispõem os Artigos 186 e 927, do Código Civil de 2002. O Artigo 186 estabelece o conceito de ato ilícito, pontuando que "aquele que, por ação ou omissão voluntária, negligência ou imprudência, violar direito e causar dano a outrem, ainda que exclusivamente moral, comete ato ilícito.”, enquanto o Artigo 927 determina a

\footnotetext{
152 “Art. $5^{\circ}$ Todos são iguais perante a lei, sem distinção de qualquer natureza, garantindo-se aos brasileiros e aos estrangeiros residentes no País a inviolabilidade do direito à vida, à liberdade, à igualdade, à segurança e à propriedade, nos termos seguintes:

(...)

V - é assegurado o direito de resposta, proporcional ao agravo, além da indenização por dano material, moral ou à imagem;

(...)

X - são invioláveis a intimidade, a vida privada, a honra e a imagem das pessoas, assegurado o direito a indenização pelo dano material ou moral decorrente de sua violação;"
} 
obrigação de indenizar pelo cometimento de ato ilícito, determinando que "aquele que, por ato ilícito, causar dano a outrem, fica obrigado a repará-lo."

Nota-se que o Art. 186 não estabelece um rol taxativo das espécies de dano cuja ocorrência configura ato ilícito, sendo perfeitamente possível incluir sob a tutela do dispositivo em comento o dano existencial. O único critério, pois, necessário para a configuração do ato ilícito é a ocorrência de ação, omissão voluntária, negligência ou imprudência da qual decorra dano à outra pessoa, independente da natureza do dano em questão.

Assim, das normas expostas, se extrai que, para que esteja configurada a responsabilidade por dano existencial, se faz necessário observar a existência de três elementos: ato ilícito, dano e nexo de causalidade entre ambos.

Porém, Alvarenga e Boucinhas Filho (ALVARENGA e FILHO, 2013, p. 245) entendem que, para além dos elementos comuns a toda forma de dano anteriormente citados, o dano existencial traz, consigo, dois elementos em particular, os quais devem ser necessariamente observados quando da constatação da ocorrência desse tipo de dano. São eles: o dano ao projeto de vida e o dano à vida de relações.

Percebe-se, portanto, que, para a doutrina pátria, o instituto do dano ao projeto de vida, ao invés de uma categoria de dano autônoma, seria, na verdade, um elemento do dano existencial, mais abrangente, abarcando, além do projeto de vida, também a vida de relações, ou seja, o seu relacionamento pleno com os demais seres humanos e a sua participação nas diversas atividades oriundas da vida em comunidade.

3.2. O "dano existencial" no direito do trabalho e a incidência da jurisprudência interamericana

Conforme já dito, o conceito de dano existencial não está previsto no corpo legislativo pátrio, situação que se estende, também, às normas de proteção ao trabalhador, tenda a responsabilidade por essa categoria de dano ter passado a ser reconhecida recentemente pelo Tribunal Superior do Trabalho e pelos Tribunais Regionais.

$\mathrm{Na}$ seara trabalhista, o dano existencial normalmente decorre da conduta do empregador que, ao explorar excessivamente a atividade do obreiro, causa ao empregado a impossibilidade de que este desfrute plenamente dos demais aspectos de sua vida.

In casu, se observa a ocorrência de dano existencial quando o empregado se encontra impossibilitado de se relacionar em sociedade por meio de atividades "recreativas, afetivas, 
espirituais, culturais, esportivas, sociais e de descanso", diretamente ligadas à manutenção de seu bem-estar, ou quando o obreiro se mostra impedido de "prosseguir ou mesmo de recomeçar os seus projetos devida, que serão, por sua vez, responsáveis pelo seu crescimento ou realização profissional, social e pessoal.” (ALVARENGA e FILHO, 2013, p. 243).

Conforme já dito, o reconhecimento do dano existencial, no direito do trabalho, emergiu diretamente da jurisprudência. Dessa maneira, é imprescindível analisar a matéria a partir do entendimento dos tribunais nacionais.

Com relação à temática da sobrejornada - campo fértil para a observação de dano existencial - o entendimento atual do Tribunal Superior do Trabalho é o de que o labor em horário extraordinário, ainda que excessivo, por si só, não conduz automaticamente à conclusão de que o obreiro tenha sofrido dano existencial. É o que, por exemplo, se extrai do Recurso de Revista 367-46.2014.5.23.0041, de Relatoria do Ministro Aloysio Corrêa da Veiga $^{153}$.

Logo, para que se constate dano existencial, é crucial que se comprove que o labor prestado em jornada que excede os limites legais, de fato, afetou substancialmente o seu plano de vida, o privando, por exemplo, do convívio familiar, de relacionamentos afetivos ou do usufruto de outros aspectos considerados caros para a vida humana.

Todavia, para a análise ora pretendida, o ponto crucial reside em identificar de qual maneira a corte suprema trabalhista está interpretando o conceito de dano existencial, no sentido de verificar se o dano existencial, no direito pátrio, está sendo entendido tal qual a Corte Interamericana compreende o dano ao projeto de vida.

Ao observar alguns excertos da jurisprudência do Tribunal Superior do Trabalho, se constata que a jurisprudência da Corte Interamericana de Direitos Humanos tem sido diretamente citada pelos Ministros no teor de seus votos, em um exemplo claro do fenômeno chamado por André de Carvalhos Ramos de “diálogo entre as Cortes” (RAMOS, 2013, p.

\footnotetext{
153 "Nas razões do recurso de revista, o reclamante insiste em que teria sofrido dano existencial pela prestação de jornadas de trabalho excessivas. (...) Cinge-se a controvérsia em definir se o cumprimento de jornada de trabalho extensa pela prestação de horas extras, por si só, implica dano existencial suficiente a ensejar dever de reparação de ordem moral. A decisão recorrida entendeu que a extensa jornada de trabalho por parte do reclamante o expôs a danos de ordem psíquica e moral, privando-o de horas de lazer e do convívio com a família. Entretanto, a jurisprudência desta Corte caminha no sentido de que o dano existencial, ao contrário do dano moral, não é presumível, ele necessita de ser provado, sob pena de desrespeito às regras do ônus da prova. O cumprimento de jornada de trabalho extensa pela prestação de horas extras, por si só, não enseja a indenização perseguida quando não demonstrada efetiva impossibilidade de convívio familiar e social, hipótese dos autos. (...)O dano existencial, ao contrário do dano moral, não é presumível - in re ipsa - ele necessita de ser provado. Para se chegar à conclusão diversa, de que houve o dano existencial apontado pela Reclamante, seria necessário o revolvimento de fatos e provas, expediente vedado nesta instância extraordinária, nos termos da Súmula 126/TST, o que inviabiliza a análise da suposta ofensa ao artigo $5^{\circ}$, X, da Constituição Federal. Precedentes. Recurso de revista não conhecido.”
} 
298) muito embora o doutrinador use essa expressão para se referir a interação entre o STF e a Corte interamericana de Direitos Humanos.

O diálogo entre as Cortes, portanto, ocorre quando as supremas cortes nacionais fazem uso da jurisprudência da Corte IDH para fundamentar as suas decisões em matéria de direitos humanos, fenômeno que, embora ainda raro no Brasil, tem se mostrado mais comum quando se observam as decisões em matéria de reconhecimento de dano existencial no direito do trabalho.

No Recurso de Revista de número 523-56.2012.5.04.0292, cujo acórdão foi publicado no DEJT em 28/08/2015, o Ministro Relator Vieira de Mello Filho afirma, em seu voto, ao tratar do dano existencial, que

(...) o conceito de projeto de vida e a concepção de lesões que atingem o projeto de vida passa a fazer parte da noção de dano existencial. A jurisprudência da Corte Interamericana de Direitos Humanos contribui para o aperfeiçoamento do conceito na medida em que tem reconhecido a incidência de dano ao projeto de vida quando ocorre violação aos direitos humanos consagrados na Convenção Americana de Direitos Humanos

Ainda, em outro exemplo, dessa vez analisando a atuação dos Tribunais Regionais, o Desembargador Flávio Villani Macêdo, da $17^{\mathrm{a}}$ Turma do Tribunal Regional do Trabalho da $2^{\mathrm{a}}$ Região, ao proferir seu voto no Recurso Ordinário de nº 0001359-93.2014.5.02.0072, também em matéria de dano existencial, entendeu da seguinte forma:

O dano existencial nada mais é do que uma modalidade de dano extrapatrimonial. Reconhecida pela Corte Interamericana de Direitos Humanos desde 1998, onde o termo mais usado é "dano ao projeto de vida", cuja definição consagrada foi dada no caso Gutiérrez Soler versus Colômbia (2005) nos seguintes termos: "dano ao projeto de vida, entendido como uma expectativa razoável e acessível no caso concreto; implica a perda ou o grave desprezo de oportunidades de desenvolvimento, de forma irreparável ou muito dificilmente reparável".

Vê-se, aqui, raros casos nos quais o juiz nacional se remete às decisões do juiz internacional para fundamentar as suas próprias decisões, tal qual recorre aos entendimentos sumulados ou, ainda, à jurisprudência dos tribunais pátrios.

Ainda que mais comum em outros países na América Latina, esse é um fenômeno de rara observação entre os tribunais brasileiros, ainda quando se discute a aplicação dos direitos e garantias salvaguardados pela Convenção Americana sobre Direitos Humanos.

Todavia, conforme defendido no tópico 2.2, a observância da jurisprudência interamericana não é mera faculdade do juiz nacional, mas, na verdade, obrigação convencional, derivada do Artigo 2 do Pacto de São José. Agindo em sentido contrário, se corre o risco de obter decisão judicial apta a ser enquadrada enquanto medida estatal 
ofensiva ao tratado, gerando, assim, a possibilidade de responsabilização internacional do Estado.

Portanto, ainda que de maneira tímida, o fato dos Tribunais Regionais e do Tribunal Superior do Trabalho estarem observando a jurisprudência interamericana para interpretar a o conceito de dano existencial e a sua aplicação na esfera doméstica, é iniciativa que pode ser enxergada enquanto um avanço, ainda que insuficiente, inegavelmente positivo.

\section{CONSIDERAÇÕES FINAIS}

O fato dos juízes nacionais estarem buscando na jurisprudência interamericana o reforço argumentativo necessário para a aplicação do dano ao projeto de vida, através da figura do dano existencial, no direito nacional, pode ser considerado um avanço em direção à plena eficácia da Convenção Americana sobre Direitos Humanos no Brasil.

Todavia, em sede de considerações finais, é importante trazer à tona a conclusão de que o diálogo entre cortes ainda não está ocorrendo de modo satisfatório, uma vez que, a jurisprudência interamericana não pode ser entendida apenas como um reforço argumentativo - como, por exemplo, a jurisprudência estrangeira. Conforme defendido no tópico 2.2, o Estado que se submete a jurisdição da Corte Interamericana possui a obrigação de decidir, no âmbito doméstico, de maneira que não contrarie a sua jurisprudência.

A discussão em matéria de direitos humanos, quando constatada a ocorrência de violação aos direitos e garantias protegidos pela Convenção Americana sobre Direitos Humanos, será objeto da atividade judicante estatal e, por conseguinte, alvo do poder de decisão dos juízes e tribunais nacionais. Dessa forma, assim como à Corte Interamericana, também cabe aos juízes e tribunais estatais a aplicação e interpretação da Convenção Americana sobre Direitos Humanos. Todavia, os agentes do direito interno devem seguir os posicionamentos da Corte Interamericana de Direitos, tendo em vista o caráter vinculante da jurisprudência interamericana em matéria de direitos humanos, cabendo, novamente, alusão ao que fora discutido no tópico 2.2.

Dessa forma, ainda que o caso do dano existencial possa configurar um bom exemplo de como a jurisprudência interamericana está, atualmente, incidindo no direito interno, é importante encerrar o presente trabalho estabelecendo que esta maneira de aplicação ainda não pode ser compreendida enquanto ideal. 


\section{REFERÊNCIAS}

ALVARENGA, Rúbia Zanotelli de; BOUCINHAS FILHO, Jorge Cavalcanti. O Dano Existencial e o Direito Do Trabalho. Rev. Tst, Brasília, v. 79, n. 2, p.240-261, abr. 2013.

CIDH. B-32: Convenção Americana sobre Direitos Humanos. Disponível em: $<$ http://www.cidh.oas.org/basicos/portugues/d.Convencao_Americana_Ratif..htm>. Acesso em: 14 nov. 2016.

CORAO, Carlos M. Ayala. La Ejecución de Sentencias de La Corte Interamericana de Derechos Humanos. Estudios Constitucionales, Santiago, v. 1, n. 5, p.127-201, 2007.

GOMES, Luiz Flávio; MAZZUOLI, Valerio de Oliveira. Comentários à Convenção Americana sobre Direitos Humanos.São Paulo: Revista dos Tribunais, 2013.

PIOVESAN, Flávia. Direitos Humanos e o Direito Constitucional Internacional. São Paulo: Saraiva, 2012.

PRESIDÊNCIA DA REPÚBLICA. Constituição da República Federativa do Brasil de $1988 . \quad$ Disponível em: <http://www.planalto.gov.br/ccivil_03/constituicao/constituicaocompilado.htm>. Aceso em: 14 nov. 2016

PRESIDÊNCIA DA REPÚBLICA. Decreto $\mathbf{n}^{\mathbf{0}}$ 4.463, de 08 de novembro de 2002. Disponível em: 〈https://www.planalto.gov.br/ccivil_03/decreto/2002/d4463.htm>. Aceso em: 14 nov. 2016

PRESIDÊNCIA DA REPÚBLICA. Lei no 10.406, de 10 de janeiro de 2002. Disponível em: <http://www.planalto.gov.br/ccivil_03/leis/2002/L10406.htm>. Aceso em: 14 nov. 2016

RAMÍREZ, Sergio García. La jurisdicción interamericana de derechos humanos (Estudios). México Df: Ediciones Corunda, 2006.

RAMOS, André de Carvalho. Responsabilidade Internacional Do Estado Por Violação De Direitos Humanos. R. Cej, Brasília, n. 29, p.53-63, abr. 2005. p. 58

RAMOS, André de Carvalho. Teoria Geral Dos Direitos Humanos na Ordem Internacional. São Paulo: Saraiva, 2013. 
SCHÄFER, Gilberto; MACHADO, Carlos Eduardo Martins. A Reparação do Dano ao Projeto de Vida na Corte Interamericana de Direitos Humanos. Revista de Direitos Fundamentais e Democracia, Curitiba, v. 13, n. 13, p.179-197, jan. 2013.

SOARES, Flaviana Rampazzo. Responsabilidade Civil por Dano Existencial. Porto Alegre: Livraria do Advogado Editora, 2009.

Tribunal Regional do Trabalho da $2^{\text {a }}$ Região. Recurso Ordinário 000135993.2014.5.02.0072. Acórdão Publicado em 20/05/2015. Disponível em: <http://aplicacoes8.trtsp.jus.br/sis/index.php/segundaInstancia> Aceso em: 14 nov. 2016

Tribunal Superior do Trabalho. Recurso de Revista 367-46.2014.5.23.0041. Acórdão Publicado em 22/03/2016 no DEJT. Disponível em:

$<$ http://aplicacao4.tst.jus.br/consultaProcessual/resumoForm.do?consulta=1\&numeroInt=292 353\&anoInt=2015> Aceso em: 14 nov. 2016

Tribunal Superior do Trabalho. Recurso de Revista 523-56.2012.5.04.0292 . Acórdão Publicado em 28/08/2015 no DEJT. Disponível em: < http://aplicacao4.tst.jus.br/consultaProcessual/consultaTstNumUnica.do?consulta=Consultar\& conscsjt $=\&$ numeroTst $=523 \&$ digito $\mathrm{Tst}=56 \&$ ano $\mathrm{Tst}=2012 \&$ orgaoTst $=5 \&$ tribunal $\mathrm{Ts}=04 \&$ vara Tst=0292\&submit=Consultar $>$ Aceso em: 14 nov. 2016

TRINDADE, Antônio Augusto Cançado. Tratado de Direito Internacional dos Direitos Humanos: Volume III. 2. ed. Porto Alegre: Fabris Ed., 2003. P. 76.

\title{
THE REFLECTIONS OF THE INTER-AMERICAN JURISPRUDENCE OF HUMAN RIGHTS IN BRAZILIAN LAW: AN ANALYSIS FROM THE APPLICATION OF THE CONCEPT OF "DAMAGE TO THE PROJECT OF LIFE"
}

\begin{abstract}
The present work is intended to investigate the impact of the American jurisprudence on human rights, especially the judgments of the Inter-American Court of Human Rights, in domestic law. To do so, we will use the example of the concept of damage to the life project, applied by the Inter-American Court, and its parallel in Brazilian law, the existential damage. In this way, first, it will be conceptualized the damage to the project of life, demonstrating the treatment given to the institute by the Inter-American Court, and then advocating the use of inter-American jurisprudence as a source of
\end{abstract}


state law. Next, it will be the institute of existential damage, addressing, especially, its application by labor law, in order to analyze whether the labor tribunals are conducting the proper observance of inter-American jurisprudence.

Keywords: Inter-American Court. Jurisprudence. Damage to the life project. Existential damage. 